\title{
Male and female students' uptake in responding to oral corrective feedback
}

\author{
Zaky Dzulhiza Hawin Amalia \\ zaky.dzulhiza@gmail.com \\ Department of English Language Education, Faculty of Teacher Training and \\ Education, Universitas Sebelas Maret Surakarta, Indonesia \\ Jalan Ir. Sutami No. 36 A, Pucangsawit, Jebres, Surakarta, Indonesia \\ Endang Fauziati \\ endang.fauziati@ums.ac.id \\ Department of English Language Education, Faculty of Teacher Training and \\ Education, Universitas Muhammadiyah Surakarta, Indonesia \\ Jalan Ir. A. Yani, Mendungan, Pabelan, Kartasura, Sukoharjo, Indonesia \\ Sri Marmanto \\ marmanto@staff.uns.ac.id \\ Department of English Language Education, Faculty of Teacher Training and \\ Education, Universitas Sebelas Maret Surakarta, Indonesia \\ Jalan Ir. Sutami No. 36 A, Pucangsawit, Jebres, Surakarta, Indonesia
}

Received: December 26, 2018; $\quad$ Accepted: March 2, 2019; $\quad$ Published: March 9, 2019

\begin{abstract}
This study aims at investigating male and female students' 'uptake' to the lecturer's oral corrective feedback (OCF). This study used a qualitative method using case study design. Thirty-nine students in the English Education Department participated in this study. They consisted of eleven male students and twenty-eight female students. All participants in this study were taking Survival Speaking class. The data were collected through observation of six hours of speaking classroom interaction. It was then analyzed through three stages: data condensation, data displays and drawing conclusion, and verification. The findings revealed that explicit correction is the most widely used and leads to the most amount of repair. The data obtained from the male students show that explicit correction leads to uptake with repair, whereas the four implicit feedback strategies i.e. clarification request, metalinguistic
\end{abstract}


feedback, elicitation, and repetition mostly lead to uptake with need-repair. Furthermore, the data obtained from the female students show that explicit correction, recast, and metalinguistic feedback mostly lead to uptake with repair, whereas clarification request, elicitation, and repetition mostly lead to uptake with need-repair. Hence, the results of this study will show us which type of oral corrective feedback induces successful feedback and uptake.

Keywords: oral corrective feedback; uptake; male and female students; foreign language teaching

How to cite this paper: Amalia, Z. D. H., Fauziati, E., \& Marmanto, S. (2019). Male and female students' uptake in responding to oral corrective feedback. Journal on English as a Foreign Language, 9(1), 107-125. doi:http://dx.doi.org/10.23971 ßefl.v9i1.1047

DOI: http://dx.doi.org/10.23971 ßefl.v9i1.1047

In language learning, errors produced by the students are seen as an indicator of progress. The previous study conducted by Simbolon (2015) discussed the particular errors in speaking activities. She clearly indicated and classified some students' grammatical errors that occurred in speaking activities. An error, according to Gitsaki and Althobaiti (2010, p. 198), is considered a natural process in learning and the evidence of the students' efforts to deliver the target language. In order to help the students to acquire the target language, errors must be properly treated and corrected.

The treatment of error produced by the students is possible through corrective feedback (CF). Phuong and Huan (2018) share their opinion that when the students produce mispronounced words or make syntactic errors, it is necessary for the students to receive corrective feedback that helps them become aware and notice their errors, and also avoid making the same errors again. If the students' errors are not corrected, the errors will become fossilized and disturb the meaning of language. The students may think that they have used English appropriately because their teacher never provides them the correction. Therefore, by providing $\mathrm{CF}$, the teacher will indicate that there are some errors in students' utterances, and then the students will notice those errors.

CF strategy plays an important role in the process of teaching a foreign language as this feedback strategy facilitates language learning and ensures linguistic accuracy and interaction from specific linguistic forms that result in 
effectively increasing communicative competence (Ellis, 2009). This view implies that $\mathrm{CF}$ is viewed as a key element in helping students improve their learning through self-correction and it can be the responses to the students' illformed utterances (Ellis, 2006, p. 28). Yoshida (2008) describes CF as the teacher's correction to the student's erroneous oral production.

There are many strategies for correcting the students' errors that need to be understood by teachers or lecturers. Lyster and Ranta (1997) introduce the six strategies of CF in the speaking classroom, namely explicit correction, recast, metalinguistic feedback, clarification request, repetition, and elicitation. Explicit correction itself occurs when the teachers immediately deliver the correct revision and clearly indicate the students' errors. A recast occurs when the teachers reformulate the students' incorrect utterances without pointing out the students' error. Metalinguistic feedback occurs when the teachers deliver the linguistics information about the students' error without informing the correct form. A clarification request occurs when the teachers indicate that they have not understood what the students said and the teachers ask the students to reformulate their utterances by saying 'Sorry' or 'Pardon me'. Repetition occurs when the teachers repeat the students' ill-formed utterances by emphasizing the intonation to highlight the students' errors. Elicitation occurs when the teachers directly elicit the students' errors to do self-correction by asking some questions related to the students' errors which require more than a yes answer or by pausing to let the students complete and revise the upcoming words (Lyster \& Ranta, 1997).

Since CF strategies are intended to help students repair their errors, students' reactions towards a given $\mathrm{CF}$ are worth studying. The students may try to correct their errors with the help from CF strategies or they can simply repeat the correct form provided by their teacher. The students' responses to a teacher's OCF have been termed uptake. Lyster and Ranta (1997) define uptake as the students' responses that immediately follow the teacher's CF strategies and that belong to the students' reaction to the teacher's CF strategies. In addition, according to Zhao (2009), uptake itself refers to the students' immediate responses after the teacher's $\mathrm{CF}$ on their errors.

Lyster and Ranta (1997) classify the term uptake into two main categories, namely, 'repair' and 'need repair.' The repair itself means that the students are able to correct the ill-formed word in a single turn after given CF by the teacher and that did not lead to additional CF. Whereas need repair category is one of the student's uptake that leads to an additional 'turn of CF moves.' In other words, Phuong and Huan (2018) underlined that repair indicates that students are able to correct their error after receiving CF from Journal on English as a Foreign Language, 9(1), 107-125 Copyright $\odot 2019$ by JEFL, p-ISSN 2088-1657; e-ISSN 2502-6615 
their lecturer, whereas need repair means that the students' utterance after receiving CF still contains the same or a different error that needs to be corrected again in the next turn of CF moves.

Actually, students' repair uptake needs the correct revision of an error, but in reality, the students' revision might differ from the modified output (Phuong \& Huan, 2018). According to Lyster and Ranta (1997), students' repair can be in the form of repetition which means students' repetition to the teacher's CF when the feedback contains the correct form. Moreover, students' repair can also be incorporation, which refers to the students' repetition to the correct form of a teacher's CF, which is then incorporated into a longer utterance. Also, students' repair can be either self-repair or peer-repair.

Phuong and Huan (2018) claim that students' uptakes with repair have a greater value than those with need repair. It is because need-repair can be a simple acknowledgment such as responding with a simple 'yes' or ' $n o$ ' to the teacher's CF moves, students' repetition of their initial errors (same error), different error, or hesitation to respond the teacher's CF. Need-repair can also be off target in response to the teacher's CF moves: their response may circumvent the teacher's linguistic focus, but without including further errors. Furthermore, need repair uptakes can also be partial repair of the initial errors and cases of either the same or different error (Phuong \& Huan, 2018).

Besides the two types of uptakes, another case that occurs is no uptake. According to Phuong and Huan (2018), no uptake is identified when students have no response to the teacher's CF moves. No uptake may happen when the teacher doesn't provide opportunities for a student's uptake, or a student may or may not acknowledge the teacher's CF and they keep talking to the teacher or their peers. Lyster and Ranta (1997) state that no uptake can occur when the students ignore the teacher's intention or when the teacher did not provide an opportunity for the students to give uptake. In this case, if no uptake has occurred, then discussion of the topic has also ceased.

Lyster and Ranta (1997) claim that uptake becomes important in the teaching and learning process for two reasons. First, uptake gives the students an opportunity to gain knowledge about the target language after receiving CF. Second, uptake helps the students to repair their utterances, notice their errors, provide the correct forms, and reform their sentences. Here, when the students are able to repair their utterances, provide the correct forms, and reform their sentences, the students have successfully delivered their uptakes. Similarly, Zhao (2009) states that a student's uptake is considered successful when the uptake demonstrates that the student has revised an error correction. In 
contrast, Lyster and Ranta (1997) claim that a student's uptake is considered unsuccessful when a student fails to demonstrate the correct revision of an error. Then, the appropriate CF strategy is needed to gain a successful uptake.

Considering the importance of $\mathrm{CF}$ strategies, the focus on student uptake is also an important aspect to be investigated. The actual target of $\mathrm{CF}$ also gives attention to the evidence of students' uptakes in classroom activities. Several studies have indicated that CF strategy with its prominent position in language teaching and learning is strongly connected to student uptake (Abaya, 2014; Fu \& Nassaji, 2016; Gitsaki \& Althobaiti, 2010; Jabu et al., 2017; Lyster \& Ranta, 1997; Nuramirah, 2017; Panova \& Lyster, 2002; Phuong \& Huan, 2018; Xu, 2012; Zhao, 2009).

Lyster and Ranta (1997) found that elicitation, metalinguistic feedback, and explicit correction have resulted in the largest amount of successful uptake. Whereas Panova and Lyster (2002) found that recast, elicitation, and clarification request led to the most uptake with a repair. Subsequently, Fu and Nassaji (2016) demonstrated that recast brought about the greatest number of students' uptakes and repairs. On the contrary, Nuramirah (2017) found that the result of explicit CF led to the most uptake. Abaya (2014) and Phuong \& Huan (2018) demonstrated their finding that metalinguistic feedback was considered the most successful $\mathrm{CF}$ because it results in repair uptake more than other CF strategies. Moreover, $\mathrm{Xu}$ (2012) found that the implicit feedback strategies were more effective in eliciting uptake, but the explicit feedback strategy yielded a lower need-repair rate, which means that the students could revise their errors more successfully when they were offered explicit feedback strategies.

These previous findings indicate that different types of OCF can lead to successful uptake. However, the particular type of OCF which led to the most successful uptake in each study was different. The difference in findings can be influenced by many factors. One of these factors can be gender, which will be revealed in the current study. Xia (2013) claimed that the issues about gender have become connected with the issue of language used. Moreover, Khorshidi and Rassaei (2013) argue that gender is one of the factors of psycholinguistic and sociolinguistic mechanisms. Here, male and female students might have different uptakes when responding to OCF. Therefore, gender might be a reason for the differences in students' uptake following OCF types. Thus, in order to see the more specific uptake differences between male and female students, investigating and analyzing their uptakes with a focus on gender is paramount.

Journal on English as a Foreign Language, 9(1), 107-125

Copyright (C) 2019 by JEFL, p-ISSN 2088-1657; e-ISSN 2502-6615 
The current study intends to find out which OCF strategies lead to the most successful uptake. In doing so, it proposes to look deeper into the male and female students' uptakes following the types of OCF from the perspective of gender. The research problems of this study are: 1) what are the male students' uptakes in responding to OCF types? and 2) what are the female students' uptakes in responding to OCF types?

\section{METHOD}

A qualitative method was employed in this research. According to Creswell (2012, p. 15), qualitative research is an inquiry process of understanding that explores social or human problems. The qualitative case study in the current study was conducted with first-year students of Sebelas Maret University located in Surakarta. Thirty-nine students in the English Education Department participated in this study. They consisted of eleven male students and twenty-eight female students. The age of the students ranged from eighteen to twenty. All participants in this study were taking Survival Speaking class. They all spoke Indonesian as their L1 and only spoke English in their classroom.

Data for the current study were collected through observation. The speaking classroom was observed directly for about six hours. The observation was performed by being present, watching, and taking notes in the classroom, with no interaction or participation in the classroom activity. This follows Creswell's (2009, p. 221) remark about what the observer has to do during classroom observation. From the observation, some data about male and female students' uptake in responding to the lecturer's OCF was obtained.

The data were validated through, first, prolonged engagement sufficient and persistent observation in the field. This refers to spending sufficient time in the field to learn or understand the culture, social setting, or phenomenon of interest. This also includes building trust with participants, learning the culture, and checking for misinformation that stems from distortions introduced by the researcher or informants. In the field (the classroom in this case), the decisions about what was salient to the study, relevant to the purpose of the study, and of interest for focus were made. Second, negative case analysis, working hypotheses as the research advances in light of negative or disconfirming evidence were refined. The initial hypotheses were revised until all cases fit, completing this process late in data analysis and eliminating all outliers and expectations. Third, clarifying research's bias from the outset of the study is also important so that the reader understands the current study's position and any biases or assumptions that impact the research. Following Creswell's (2012)

Journal on English as a Foreign Language, 9(1), 107-125

Copyright $\odot 2019$ by JEFL, p-ISSN 2088-1657; e-ISSN 2502-6615 
recommendation, comments on past experiences, biases, prejudices, and orientations that have likely shaped the interpretation and approach, were included in the current study.

In analyzing the data, this study used the Interactive Model of qualitative research used by Miles and Hubberman (2014). They classified the steps for analyzing the data into 3 parts, such as data condensation, data displays and drawing conclusion and verification. Firstly, the data obtained from classroom observation about students' uptakes following the different types of OCF were analyzed in the data condensation step through various processes such as selecting, focusing, simplifying, abstracting, and transforming. Here, the data regarding OCF types used by the lecturer (Explicit Correction, Recast, Clarification Request, Metalinguistic Feedback, Elicitation, and Repetition) and the data for students' uptake (Repair and Need Repair) were coded based on the theory. After that, OCF types used by the lecturer (Explicit Correction, Recast, Clarification Request, Metalinguistic Feedback, Elicitation, and Repetition) were analyzed to see which types of uptakes (Repair and Need Repair) followed OCF types. After knowing which uptakes (Repair and Need Repair) followed OCF types, the successful and unsuccessful uptakes were identified. If the OCF types didn't lead to an additional turn of feedback, the uptake was considered successful. If the OCF types led to an additional type of feedback, the uptake was considered unsuccessful. After that, the data was displayed as the information that leads to conclusion drawing and action taking. The last stage of data analysis was drawing a conclusion and verification. In this stage, the conclusion about male and female students' uptakes in responding to the different types of lecturer's feedback is demonstrated. Finally, the data was verified using theories about uptakes and previous studies.

\section{FINDINGS}

\section{Male Students' Uptakes in Responding to OCF Types}

This section investigates the students' uptakes following the different CF strategies. About 104 feedback moves were provided to male and female students during six hours of classroom interaction. Those feedback moves, then, are identified to see which feedback types actually lead to repair (successful uptake), need-repair (unsuccessful uptake) or even no uptake (unsuccessful uptake). Table 1 shows the distribution of male students' uptakes (repair/needrepair) in responding to the OCF moves. 
Table 1. Male Students' Uptake in Responding to OCF

\begin{tabular}{llccccccc}
\hline \multirow{2}{*}{ No } & \multirow{2}{*}{ Types of OCF } & \multirow{2}{*}{ OCF } & \multicolumn{2}{c}{ Repair } & \multicolumn{2}{c}{$\begin{array}{c}\text { Need } \\
\text { Repair }\end{array}$} & \multicolumn{2}{c}{ No Uptake } \\
\cline { 3 - 11 } & & Total & $n$ & $\%$ & $n$ & $\%$ & $n$ & $\%$ \\
\hline 1 & Explicit Correction & 23 & 17 & 72.73 & 6 & 27.27 & - & - \\
\hline 2 & Recast & 0 & - & - & - & - & - & - \\
\hline 3 & Clarification Request & 4 & 1 & 25 & 3 & 75 & - & - \\
\hline 4 & Metalinguistic & 2 & - & - & 2 & 100 & - & - \\
\hline 5 & Elicitation & 11 & 3 & 27.27 & 6 & 54.55 & 2 & 18.18 \\
\hline 6 & Repetition & 2 & - & - & 1 & 50 & 1 & 50 \\
\hline & Total & 42 & 21 & 50 & 18 & 42.86 & 3 & 7.14 \\
\hline
\end{tabular}

According to Table 1, the lecturer provided 42 OCF moves to the male students. Out of 42 feedback moves, 23 were an explicit correction and the most widely provided. The lecturer also provided 11 moves of elicitation, 4 moves of clarification request, and 2 moves each of both metalinguistic feedback and repetition. However, the lecturer did not provide any recast type for the male students.

Among those 42 moves, the explicit correction had the highest degree of success. When the lecturer explicitly corrected the error, uptakes were $72.73 \%$ repair and $27.27 \%$ need repair. Because the percentage of uptakes with repair was higher than uptakes with need repair. This means that the male students were able to reformulate the feedback correctly so that explicit correction did not lead to an additional turn of feedback. Following is an example of what happened in the first recorded session.

Example 1:

S : Go straight/strait/ this road.

L : Not straight/strait/, but straight/strert/. Go straight/strest/ this road. (Explicit Correction)

MS : Go straight/streIt/ this road. (Repetition, Repair)

(Observation/FN01/June/2018)

In this example, the class is talking about finding the way. The male student is chosen to practice. He produces an incorrect pronunciation. He says /strart/ instead of /strert/. The male lecturer clearly indicates that the pronunciation of the word Straight is incorrect. After that, he provides a clear correction for it. The student, then, incorporates the utterance into a correct form. In this case, the lecturer's correction is clear enough, so that the student easily revises his error correctly and the uptake was successful. 
On the contrary, as presented in Table 1, the implicit feedback strategies such as clarification request, metalinguistic feedback, elicitation, and repetition mostly lead to unsuccessful uptakes. From the result, we clearly see that the percentage of uptakes with need repair following those four types is greater than that of uptakes with the repair. Those four types lead to additional turns of feedback.

When the lecturer corrected the male students' errors by using 4 moves of clarification requests, the rate of uptakes was $25 \%$ repair and $75 \%$ needrepair. Here, the rate of need for repair is higher. For metalinguistic feedback, when the lecturer gave 2 moves of metalinguistic feedback to correct the students' error, the male students responded to them with need repair. For elicitation, when the lecturer corrected the students' errors by using 11 moves of elicitation, the rate of uptake was $27.27 \%$ repair, $54.55 \%$ need repair and $18.18 \%$ no uptake. For repetition, when the lecturer corrected by using 2 moves of repetition, uptake was 50\% need repair and 50\% no uptake. Here, need repair and no uptake both lead to additional turns of feedback.

These four implicit feedback strategies (clarification request, metalinguistic feedback, elicitation, and repetition) invite the students to selfcorrection and force them to think because the lecturer does not provide them the correction explicitly. The result is that uptakes following those feedback techniques mostly lead to an additional turn of feedback due to the students' tendency to repeat the ill-formed words. This is what happened in the first recorded session below.

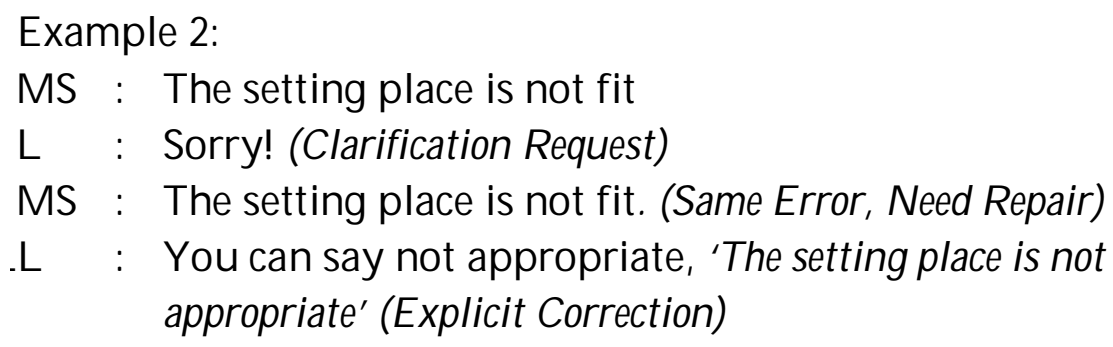

(Observation/FN01/June/2018)

Here, the male student is asked to share his opinion. He, then, produces an error in his choice of vocabulary. In the first turn, the lecturer corrects his error by using clarification request 'Sorry?'. The student repeats his ill-formed utterance and the same error remains. This leads to other turns of CF. After that, the lecturer provides an explicit correction to correct the student's error. In this case, repeating the same error may be due to the fact the student does not know the lecturer's meaning when he says Sorry until he produces the same error.

Journal on English as a Foreign Language, 9(1), 107-125

Copyright (C) 2019 by JEFL, p-ISSN 2088-1657; e-ISSN 2502-6615 


\section{Female Students' Uptakes in Responding to OCF Types}

Following male students' uptakes to OCF types, the distribution of female students' uptakes following OCF are presented in Table 2.

Table 2. Female Students' Uptake in Responding to OCF

\begin{tabular}{ccccccccc}
\hline \multirow{2}{*}{ No } & \multirow{2}{*}{ Types of OCF } & \multicolumn{2}{c}{$C F$} & \multicolumn{2}{c}{ Repair } & \multicolumn{2}{c}{ Need Repair } & \multicolumn{2}{c}{ No Uptake } \\
\cline { 3 - 9 } & Total & $n$ & $\%$ & $n$ & $\%$ & $n$ & $\%$ \\
\hline 1 & Explicit Correction & 22 & 17 & 77.27 & 5 & 22.73 & - & - \\
\hline 2 & Recast & 3 & 2 & 66.67 & 1 & 33.33 & - & - \\
\hline 3 & Clarification Request & 5 & 2 & 40 & 3 & 60 & - & - \\
\hline 4 & Metalinguistic & 9 & 5 & 55.56 & 4 & 44.44 & - & - \\
\hline 5 & Elicitation & 20 & 5 & 25 & 14 & 70 & 1 & 5 \\
\hline 6 & Repetition & 3 & 1 & 33.33 & 1 & 33.33 & 1 & 33.33 \\
\hline & Total & 62 & 32 & 51.61 & 28 & 45.16 & 2 & 3.23 \\
\hline
\end{tabular}

According to Table 2, the lecturer provided 62 OCF moves to the female students. Out of 62 feedback moves, 23 moves of explicit correction made it the widest type of OCF provided to the female students. Furthermore, the lecturer also engaged in 20 moves of elicitation, 9 moves of metalinguistic feedback, 5 moves of clarification request, and 3 moves each of both recast and repetition.

Among the 62 moves, the explicit correction type provided to the female students also had the highest degree of success. When the lecturer explicitly corrected the female students' errors, uptake $77.27 \%$ repair and $22.73 \%$ need repair. The female students were able to reformulate the feedback correctly so that the explicit correction did not lead to an additional turn of feedback.

Subsequently, other types of CF which also had a degree of success were recast and metalinguistic feedback. In recast, when the lecturer made 3 moves of the recast, the female students answered those moves with 2 uptakes with repair $(66.67 \%)$ and a single uptake with need repair $(33.33 \%)$. In this case, the lecturer reformulated the student's error by asking a simple question which did not interrupt the flow of conversation, so that the student could reformulate the erroneous part of her phrase easily. This is what happened in the third recorded session below:

Example 3:

FS : The first expression that Reyzon said to her friends was 'I' $m$ terribly sorry guys, I forgot to send email to Mr. Hasan'. She also gave an excuse by saying, 'That was my fault'. Her friends answered it and they are Journal on English as a Foreign Language, 9(1), 107-125

Copyright (C) 2019 by JEFL, p-ISSN 2088-1657; e-ISSN 2502-6615 


\author{
angry ...mmmmm... (thinking) \\ L : Then, are they angry? (Recast) \\ FS : Oh... yes, they are angry. Her friends were angry \\ with Reyzon. Rey said, 'How in the world you \\ manage to forget it. It is $\mathrm{mmmmm}$ showing anger to \\ Reyzon. (Incorporation, Repair)
}

(Observation/FN02/June/2018)

In example 3, we can see that the lecturer is recasting the student's illformed utterance. The lecturer asks one of her students to tell the expression displayed in the role play. The female student describes the expression and produces an error in grammar 'They angry'. In order to implicitly correct the error, the lecturer reformulates part of student's utterance. The reformulation of the student's error is provided without pointing it out. Finally, the student perceives the lecturer's feedback correctly and the flow of communication is not broken. Thus, recasting is a way of providing feedback and additional input without breaking the flow of communication.

For metalinguistic feedback, the lecturer invited the female students to perform self-correction by giving them clues from their erroneous part. When the lecturer provided 9 moves of metalinguistic feedback, the female students responded to them with five uptakes with repair $(55.56 \%)$ and four uptakes with need repair $(44.44 \%)$. Here, the ratio of uptake with repair was greater. In this case, the clues from the lecturer helped the female students to correct their errors. This is what happened in the fourth recorded session below.

\section{Example 4:}

$\mathrm{L}$ : Ok, and then what is the expression of anger from the roleplay?

FS : Oh my God. (the student hesitates and speaks without expression)

L : Sorry? (Clarification Request)

FS : Oh my.......God, you.... are so.... noisy. (She speaks haltingly and expressionlessly) (Same Error, Need Repair)

L : Use your expressive face and high intonation! Imagine that your friend is so noisy and you are angry with that one. (Metalinguistic Feedback)

FS : OH MY GOD! YOU RE SO NOISY! (Self-Repair, Repair)

(Observation/FN02/June/2018) 
In example 4, the students are asked to pay attention to their friend's performance and list the expression she used. The female student was asked to repeat the expression of anger used by the role-player. The female student hesitates to answer and repeats the role-players precise words with no expression. In the first turn of correction, the lecturer clarifies the student's error by saying sorry. The student responds to it with the same error. The lecturer, then, provides an additional turn of feedback and tells the student to use an expressive face and high intonation. Finally, the female student reformulates her sentence correctly. In this case, metalinguistic feedback leads to successful uptake.

In contrast, as presented in Table 2, clarification request, elicitation, and repetition mostly lead to unsuccessful uptakes. When the lecturer corrected the female students' errors by using five moves of clarification request, the female students responded to those moves with 2 uptakes of repair $(40 \%)$ and 3 uptakes of need repair $(60 \%)$. Here, need repair was higher. When the lecturer corrected by using 20 moves of elicitation, the female students answered it using 5 uptakes of repair (25\%), 14 uptakes of need repair $(70 \%)$, and a single no uptake $(5 \%)$. Here, the ratio of need repair was higher. When the lecturer corrected them using 3 moves of repetition, 1 uptake was repair, 1 need repair, and 1 no uptake, or $33.33 \%$ each. Here, need repair and no uptake lead to additional turns of feedback.

These three feedback strategies provided to the female students (clarification request, elicitation, and repetition) invited them to perform selfcorrection where they were forced to think without being given a clue or an exact correction. The result was that most of the uptakes following those feedback strategies mostly lead to additional feedback moves.

\section{DISCUSSION}

Based on the OCF strategies provided to the male and female students, the current study showed that male and female students have different responses for each OCF. Among all the different types of OCF provided to the male and female students, the explicit correction had the highest degree of success for both genders. The OCF provided to the male students that were least successful was clarification request, while the least successful for female students was elicitation. For metalinguistic feedback, when it was provided to the male students, the rate of need repair was higher. When it was provided to the female students, the rate of repair was higher. Thus, metalinguistic feedback provided to the male students mostly lead to additional turns of feedback, but it mostly lead to successful uptakes when provided to the female students. In

Journal on English as a Foreign Language, 9(1), 107-125

Copyright $\odot 2019$ by JEFL, p-ISSN 2088-1657; e-ISSN 2502-6615 
addition, when recast was used with female students, the rate of repair was higher, making for successful uptakes. Finally, repetition, clarification request, and elicitation provided to the male and female students mostly led to need repair for both genders.

The current finding that explicit correction leads to more uptakes with repair supports many researchers' findings (Haghani, 2012; Jabu et al., 2017; Leiter, 2010; Milicev, 2014; Nuramirah, 2017; Xu, 2012). They found that explicit correction led to the highest number of uptakes with the repair. Leiter (2010) and Jabu et al.'s (2017) finding revealed that explicit correction mostly led to repetition which is included in uptake with the repair. Xu (2012) demonstrated her finding that explicit feedback yielded a lower need-repair rate. From these studies, I believe that explicit correction makes it easier for students to revise their errors because the correct form has already been provided for them.

Moreover, the finding that metalinguistic feedback provided to the female students mostly lead to repair supports some research as well (Jabu et al., 2017; Phuong \& Huan, 2018; Zoghi \& Nikoopour, 2013). These researchers found that metalinguistic feedback mostly led to uptake with a repair. They also claimed that providing guiding questions or even information about the error helped the students to gain new insight and fix the error after guidance from the teacher. Conversely, the finding that metalinguistic feedback provided to the male students mostly lead to need repair supports Fu and Nassaji,'s (2016) finding. Most researchers have found that metalinguistic feedback is effective and leads to uptakes with a repair. However, I believe that metalinguistic feedback helps students more by providing guiding information or a clue about their error.

The finding that clarification request, elicitation, and repetition mostly lead to need repair was in line with many researchers' findings (Gitsaki \& Althobaiti, 2010; Leiter, 2010; Phuong \& Huan, 2018; Taipale, 2012). These researchers found that clarification request led to the same error being repeated. Gitsaki and Althobaiti (2010) found that elicitation had the lowest rate of successful uptake. Phuong and Huan's (2018) finding revealed that clarification request, elicitation, and repetition led to greater need-repair. In some cases, some students will find it difficult to perform self-correction due to their lack of background knowledge. Therefore, it is assumed that clarification request, elicitation, and repetition invite students to perform self-correction without being given any clue; the students who do not succeed likely have a lack of background knowledge that can be applied and thus, find it difficult to come up with a correct answer. 
However, the finding in regards to recast is different than that of many previous studies. In the current study, recast provided to the female students mostly led to uptake with a repair. There are several previous findings which similarly revealed that recast led more to uptake with repair (Alsolami \& Elyas, 2016; Fu \& Nassaji, 2016) and the students' tendency to recast (Fu \& Nassaji, 2016; Katayama, 2007; Panova \& Lyster, 2002). In Fu and Nassaji's (2016) finding, they stated that among the different feedback types, both the teacher and the students were quite accurate in perceiving recast.

On the other hand, there is some research which found that recast leads more to unsuccessful uptake (Leiter, 2010; Milicev, 2014; Phuong \& Huan, 2018; Taipale, 2012; Xu, 2012). These studies found that recast mostly led to a greater need for repair. This difference in findings shows that recast still needs to be investigated deeply. Perhaps the difference is due to how the teacher delivers recast to correct the students' error. From this, I assume that recast can lead to repair, need repair, or even no uptake based on how the teacher delivers recast to the students. Thus, the delivery of recast needs to be investigated in more detail.

In regard to gender differences, the researcher found that female students have a higher self-repair and hesitation than male students. This can be linked to the theory of men and women's language (Xia, 2013). Men's language is considered direct, clear, and assertive so that men will not hesitate to say something, even expletive words (Xia, 2013). Unlike men, women's language is more evaluative. In this case, women will become more conscious and careful in speaking (Xia, 2013). Moreover, Else-Quest et al. (2006) also state that girl students are shown to be more able to manage and regulate their attention. Carvalho et al.'s (2014) statement is also in line with that. They claimed that girls were more critical than boys in their concern over the quality of $\mathrm{CF}$ they received. From these studies, it is assumed that the negative effect of female students' carefulness and consideration in speaking is greater hesitation; whereas the positive effect may be greater self-repair in responding to the lecturers' feedback.

Overall, the current study's findings of male and female students' uptakes showed many similarities and differences with previous ones. The similarities between the current findings and the majority of the previous findings are that explicit correction and metalinguistic feedback mostly lead to uptake with repair, whereas clarification request, repetition, and elicitation mostly lead to uptake with need repair. The major difference was related to recast. This current finding showed that recast mostly leads to uptake with repair, but some previous findings demonstrated that recast mostly leads to Journal on English as a Foreign Language, 9(1), 107-125 Copyright (C) 2019 by JEFL, p-ISSN 2088-1657; e-ISSN 2502-6615 
uptake with need repair. Therefore, every type of OCF will affect the quality of students' uptake. It can be assumed that even though explicit correction showed a lower contribution to both male and female students' language acquisition, this type led more often too successful uptakes. In the case of implicit feedback, metalinguistic feedback is helpful enough to produce uptakes with repair by providing clues to acquire the target language.

\section{CONCLUSION}

The result of this study revealed that explicit correction provided to the male students brought about the highest degree of success. They were able to reformulate the feedback correctly so that explicit correction did not lead to an additional turn of the feedback sequence. On the contrary, Oral Corrective Feedback (OCF) strategies provided to the male students that led to an additional turn of feedback were clarification request, metalinguistic feedback, elicitation, and repetition.

For female students, the explicit correction type also resulted in the highest degree of success. Subsequently, other types of OCF provided to the female students which did not lead to an additional turn of feedback were recast and metalinguistic feedback. Whereas, the types of OCF provided to them that led to the further turns of feedback were clarification request, elicitation, and repetition.

The findings are intended to inform EFL teachers and lecturers about how to correct their students' errors properly. OCF will not always impede the flow of communication. When errors appear, the teachers or lecturers can respond to them in a natural way without discouraging the students and that will also facilitate language learning. The teachers or lecturers may choose from the different OCF strategies when treating and correcting the students' errors. After providing OCF, teachers or lecturers may offer opportunities for students to react and respond. For example, they may provide some hints to elicit the students' self-correction or spare one or two seconds for students to repair.

The current study also implies that in order to help the students acquire the second language, a students' error needs to be corrected by their teachers or lecturers. The teachers or lecturers can use the six strategies of OCF proposed by Lyster and Ranta (1997) such as explicit correction, recast, clarification request, metalinguistic feedback, elicitation, and repetition. Teachers and lecturers may choose from different OCF strategies when correcting the students' errors.

Journal on English as a Foreign Language, 9(1), 107-125

Copyright (C) 2019 by JEFL, p-ISSN 2088-1657; e-ISSN 2502-6615 
When providing corrective feedback, teachers may offer opportunities for learners to react and respond which is called uptake. Uptake is possible when students are actively involved in the learning process. Giving students a chance to respond to the teacher's OCF will lead them to be active in the class. By knowing the students' likely uptake when responding to the teacher's OCF, the teacher will easily know which type of OCF will most likely be successful. A teacher needs the appropriate OCF for the students because he/she needs to enhance the students' knowledge of the target language. As such, acquiring English as a foreign language needs a high contribution from both lecturers and students. One of the factors that help teachers to know how well the students learn L2 is OCF. By using OCF, the students can manage their learning in order to increase their ability.

In the current study, the student showed differences in reacting to the lecturer's feedback. Those different reactions or uptakes towards OCF types might be based on a variety of factors. Therefore, for further research, it would be interesting to investigate these factors as well as students' perceptions about OCF strategies and their own uptakes.

\section{REFERENCES}

Abaya, R. (2014). Corrective feedback in English language teaching and learning: Which way to go? International Journal on Studies in English Language and Literature, 2(10), 5-12.

Alsolami, E. H., \& Elyas, T. (2016). Investigating teachers' corrective feedback and learners' uptake in the EFL classrooms. International Journal of Educational Investigations, 3(1), 115-132.

Carvalho, C., Santos, J., Conboy, J., \& Martins, D. (2014). Teachers' feedback: exploring differences in students' perceptions. Procedia - Social and Behavioral Sciences, 159, 169-173. https://doi.org/10.1016/.sbspro.2014.12.351

Creswell, J. W. (2009). Research design: Qualitative, quantitative, and mixed methods approaches. California: SAGE Publications.

Creswell, J. W. (2012). Qualitative inquiry and research design: Choosing among five approaches. California: SAGE Publications.

Ellis, R. (2006). Researching the effects of form-focused instruction on L2 acquisition. AILA Review, 19(1), 18-41. https://doi.org/10.1075/aila.19.04ell 
Ellis, R. (2009). Corrective feedback and teacher development. L2 Journal, 1(1), 3-18.

Else-Quest, N. M., Hyde, J. S., Goldsmith, H. H., \& Van Hulle, C. A. (2006). Gender differences in temperament: A meta-analysis. Psychological Bulletin, 132(1), 33-72.

Fu, T., \& Nassaji, H. (2016). Corrective feedback, learner uptake, and feedback perception in a Chinese as a foreign language classroom. Studies in Second Language Learning and Teaching, 6(1), 159. https://doi.org/10.14746/ssllt.2016.6.1.8

Gitsaki, C., \& Althobaiti, N. (2010). ESL teachers' use of corrective feedback and its effect on learners' uptake. The Journal of Asia TEFL, 7(1), 197-219.

Haghani, M. (2012). Corrective feedback and the students' uptake. ELT Weekly, 4(1). Retrieved from http://eltweekly.com/2012/03/vol-4-issue-11research-paper-corrective-feedback-and-the-students-uptake-bymastaneh-haghani/

Jabu, B., Noni, N., Talib, A., \& Syam, A. (2017). Lecturers' use of corrective feedback and students' uptake in an Indonesian EFL context. Global Journal of Engineering Education, 19(1), 82-87.

Katayama, A. (2007). Students' perceptions toward corrective feedback to oral errors. Asian EFL Journal, 9, 289-305.

Khorshidi, E., \& Rassaei, E. (2013). The effects of learners' gender on their preferences for corrective feedback. Journal of Studies in Learning and Teaching English, 1(4), 71-83.

Leiter, J. (2010). Corrective feedback and uptake in the advanced learner classroom. Wien University, Austria.

Lyster, R., \& Ranta, L. (1997). Corrective feedback and learner uptake. Studies in Second Language Acquisition, 19(1), 37-66. https://doi.org/10.1017/S0272263197001034

Miles, M. B., \& Hubberman, A. M. (2014). Qualitative data analysis: A methods sourcebook (the $3^{\text {rd }}$ ed.). California: SAGE Publications.

Milicev, J. (2014). Correct me if I'm wrong, but do it right: Error correction and learner uptake in university-level EFL classrooms. Athens Journal of Philology, 1(4), 259-271. 
Nuramirah, P. (2017). An Analysis of teacher's corrective feedback and learners' uptake in dialogue journal. In Proceedings of the Ninth International Conference on Applied Linguistics (CONAPLIN 9). Bandung, Indonesia: Atlantis Press. https://doi.org/10.2991/conaplin-16.2017.70

Panova, I., \& Lyster, R. (2002). Patterns of corrective feedback and uptake in an adult ESL classroom. TESOL Quarterly, 36(4), 573-595. https://doi.org/10.2307/3588241

Phuong, T. T. B., \& Huan, N. B. (2018). Teacher corrective feedback on students' speaking performance and their uptake in EFL classes. European Journal of Foreign Language Teaching, 3(3), 110-131. https://doi.org/10.5281/zenodo.1321246

Simbolon, M. (2015). An analysis of grammatical errors on speaking activities. Journal on English as a Foreign Language, 5(2), 71. https://doi.org/10.23971 ßjefl.v5i2.368

Taipale, P. (2012). Oral errors, corrective feedback and learner uptake in an EFL setting. University of Jyvaskyla, Finland.

Xia, X. (2013). Gender differences in using language. Theory and Practice in Language Studies, 3(8), 1485-1489. https://doi.org/10.4304/tpls.3.8.14851489

Xu, S. (2012). An investigation into teachers' corrective feedback in Chinese EFL classrooms. Chinese Journal of Applied Linguistics, 35(4). https://doi.org/10.1515/cjal-2012-0035

Yoshida, R. (2008). Teachers' choice and learners' preference of corrective feedback types. Language Awareness, 17(1), 78-93. https://doi.org/10.2167/a429.0

Zhao, B. (2009). Corrective feedback and learner uptake in primary school EFL classrooms in China. The Journal of Asia TEFL, 6(3), 45-72.

Zoghi, A., \& Nikoopour, J. (2013). The interface of error types, teacher's feedback, and students' uptake. International Journal of Applied Linguistics $\mathcal{E}$ English Literature, 3(1), 54-62. https://doi.org/10.7575/aiac.ijalel.v.3n.1p.54 


\section{Authors' Brief CV}

Zaky Dzulhiza Hawin Amalia is a graduate student at the English Education Department, Sebelas Maret University of Surakarta, Indonesia. She received a Bachelor's degree at the English Education Department of IAIN Surakarta in 2015. Her research interests are in linguistics, foreign language teaching, and corrective feedback.

Endang Fauziati is a senior lecturer at Muhammadiyah University of Surakarta and Sebelas Maret University of Surakarta, Indonesia. She got her master degree (in 1999) in applied linguistics at the Catholic University of Atmajaya Jakarta and her doctorate degree at the same university (in 2004). Her research interests are learner errors, interlanguage, foreign language teaching, and SLA.

Sri Marmanto is a senior lecturer at Sebelas Maret University of Surakarta. He received his bachelor degree (in 1998) at Sebelas Maret University. He got his master degree (in 2010) at Udayana University. Then, he received his doctorate degree at Sebelas Maret University. His interest is mainly on the linguistics area. 